they will be endorsed by the majority of those engaged in this work at present.

The second proposal concerns the farm institutes. These are to be multiplied in number, but the provision of agricultural education at the farm institute level and below will remain a function of the local authority. In this sense the Government has wisely accepted the criticisms levelled against the Luxmore proposals. Discussions have proceeded as to the control which should operate in the case of the farm institutes, and as a piece of permanent machinery a joint advisory committee is to be set up by the Ministry of Agriculture and the Board of Education to advise on the general educational policy and methods of training at farm institutes, and in turn the institutes will be inspected by inspectors of the Board of Education and of the Ministry of Agriculture. It is a pleasing thought that the Government is now recognizing that steps must be taken at an early date to make available farm institute training, since it has been little short of a national catastrophe that the existing institutes were closed down at the beginning of the War and educational work at this level has practically ceased. The explanation is that staffs normally engaged in this work were diverted to the needs of food production; but since there has been a considerable influx of new blood into agricultural education work directly concerned with food production since the beginning of the War, it should now be possible to provide adequate staff for the re-opening of farm institutes at an early date. This will be in the best interests both of food production and the future of agriculture itself in Great Britain.

\section{Social Security in the United States}

IN the discussions on social security in Great Britain, it has already been emphasized that, at least in part, social security is an international problem. Full employment, or the reasonably high level of employment pre-supposed in the Beveridge plan, depends on the general condition of world trade as well as on the social and economic policies pursued internally in Great Britain. For that reason alone the article on "Social Security Planning in the United States", contributed by Eveline M. Burns to Agenda of December 1943, is of general interest. It gives an appreciation of the general situation in the United States and of the lines of development and policy recommended in the Security, Work and Relief Policies Report of the National Resources Planning Board, the Wagner Bill proposing to set up a unified national system of social insurance, and the more recent report of the Planning Board on "Demobilization and Readjustment", which shows the complexity of the situation in the United States.

Any acceptable and realistic programme for the United States must take account of the great geographical diversity in living standards and real wage levels, and must be so devised as to operate within the limitations of a federal system of government in which the consciousness of State rights is very strong. Furthermore, many sections of the public still regard government action to assure the basic economic security of the individual with the gravest suspicion. Social security planning of the type envisaged by the National Resources Planning Board meets with strong opposition among those who believe that the job can be done by private enterprise. Moreover, there has been a surprising lack of public interest in the proposals of the report on demobilization and readjustment, with its emphasis on the vital importance of efforts to assure full employment and on the responsibility of the Federal Government to announce its vitally important policies as soon as possible for both economic and social reasons. The whole psychological attitude of Americans, and the present boom, tend to conceal the inadequacy of American social machinery for grappling with the problems of poverty and insecurity; and no great national ordeal comparable to the 'blitz' in Great Britain has strengthened the sense of communal responsibility and the desire to remedy some of the glaring social evils of the prewar world.

\section{Planetaria of the World}

Mr. Roy K. Marshatl has an article on the Planetarium in Sky and Telescope of November 1943, which announces the first public demonstrations in the Fels Planetarium of the Franklin Institute in Philadelphia. The remainder of the article is devoted to a historical survey of the planetaria which have been constructed at various times, starting with Archimedes, the story of whose machine for reproducing the motions of the planets is probably legendary. The first of such machines to be made, of the quality of which we can be certain, was constructed by Johannes van Ceulen de la Haye, in 1682, and it is still preserved in Leyden. The proper way to represent the heavens is to make a celestial globe so large that the observer can get inside it, and the most famous of these is the one constructed about 1758 by Roger Long, the first Lowndean professor of astronomy and geometry at Cambridge. It was about $18 \mathrm{ft}$. in diameter and thirty people could be accommodated on the platform inside it.

A list of known planetaria with dates and also the diameters of the domes is given. Of twenty-seven planetaria, twelve are installed in Germany, the largest, with a diameter of $98 \mathrm{ft}$., being at Düsseldorf, and the United States comes next in the list with a total of six. A short description of some of the instruments and also diagrams appear, and the subject will be continued in a later issue. It may be mentioned, though it is probably known to most readers already, that the name 'orrery', which is frequently applied to these instruments, is derived from the fourth Earl of Orrery (Charles Boyle), for whom John Rowley made an instrument. This was an improvement on the model made by George Graham for Prince Eugene shortly after 1700.

\section{An Attack on Logical Positivism}

THE simple solution to philosophical problems, which those philosophers who describe themselves as logical positivists have propounded in the last ten years, are to-day coming under attack. In the issue of Mind of October 1943, Mr. John R. Reid, who, like many American philosophers, uses a rather elaborate and top-heavy nomenclature, in his article "Analytic Statements in Semiosis" strikes hard at the root of logical positivism by attacking its account of the distinction between analytic and synthetic statements. Briefly, according to the logical positivists, an analytical statement, for example, "Red is a colour", asserts no matter of fact, cannot be denied without self-contradiction, and needs no verification; whereas a synthetic statement, such as "What I see now is red", states matter of fact, can be denied without self-contradiction, and needs to be verified. An analytical statement needs no verifica- 
tion because it says nothing about anything; it merely illustrates our verbal habit. In saying "Red is a colour", I am merely illustrating the verbal habit we have of grouping the class of things we call red under a larger class which we call coloured. If, however, I say "What I now see is red", this is no question of verbal habits, but a matter of fact, and what makes it true or false is just what I am seeing now.

Mr. Reid argues that this is not the whole story, pleading that verification is needed even in the case of the analytic statement. What he says, reduced to very simple terms, is this : "Verbal habits are not known to me by any mysterious form of cognition. The analytic statement ' $R e d$ is a colour' must be verified by the same sort of process as the synthetic statement 'What I now see is red'. I must check how people do in fact use words such as red and colour. I must check just what my own use is (because it is my own use does not prevent me being ignorant about it) and what I intend my use to be. Rules of English change, and as they change, it may be expected that analytic statements will change with them." In Mr. Reid's view, then, both analytic and synthetic statements require to be verified, the former by the intentions and verbal habits of people, the latter by facts and natural laws. The point is one wbich was worth making though it may not reduce the structure of logical positivism to ruins.

\section{Problems of Colonization}

UNDER the title "Ideas Sobre Los Fundamentos Bioclimaticos Y Biogeographicos Para Una Colonizacion Europea", in De Goea, Anales de la Sociedad Argentina de Estudios Geográficos (7, 99-111), Walter Knoche sets forth a number of important points to be observed if colonization is to be a success. As a general principle, it is laid down that woods and forests should be protected, as they are valuable in preserving the climate, to say nothing of their aesthetic value and their use to future generations in preventing the spread of steppe and desert. Problems relating to the acclimatization of European colonies in different latitudes are considered, and also the difference in the aptitude for acclimatization of European immigrants from southern Europe or from the Mediterranean countries in comparison with those from north-west and central Europe. It is interesting to know that in torrid zones no colonists from north and central Europe are found who have any real expectations for their descendants, but this does not apply to certain southern European colonists. The difficulties of acclimatization in torrid zones are discussed and also the effects of certain climatic conditions, such as ultra-violet light which acts very differently in regions of high altitude, in temperate zones, and in tropical countries. Very short waves produce erythema while those that are longer are responsible for the formation of pigment which, while it reflects some heat, also absorbs some and, as a consequence, there ensues hypertension of the sweat glands. The southern European is better protected against the solar radiation in torrid regions than is the northern European, though the latter is now able to acquire an artificial pigment by means of sun bathing or special heat rays. The principle laid down by the Incas is recommended : "Colonize in the valleys similar to those existing in the previous State, and other parts of the earth with temperature and conditions like those from which we came; if cold, select cold ; if hot, select hot".

\section{Bell Laboratories Photographic Department}

PнотоgRAPHy is a necessary part of research and development work; and there has been a Photographic Department at the Bell Laboratories, 463 West Street, New York, ever since the building was erected for the Western Electric Company at the close of the last century. Beginning with a single photographer and camera, it grew with the organization it served until in 1941 it required the full time of nine men, and included developing and printing quarters and a studio with cameras and other facilities that permitted it to turn out some 4,500 negatives and 63,000 prints each year. By this time the facilities were old and needed replacement. A careful study was therefore made of all needs and the most efficient production methods, and an entirely new lay-out was made, new equipment acquired, and all needed facilities provided to do the work most efficiently. This new lay-out was just about completed when war came, bringing with it intensified work, longer hours and increased personnel, and there is no doubt that the greatly augmented demands for photographic services of various types would have greatly exceeded. the capacities of the old facilities. With the new quarters and equipment, a staff of fifteen is now producing at the rate of 14,000 negatives and nearly 200,000 prints a year. The new quarters are described and illustrated in an article by $\mathrm{E}$. Vain Horn (Bell Lab. Rec., 22, No. 2 ; October 1943).

\section{Conductor Sagging on Overhead Lines}

Messrs. C. O. Boyse and N. G. Simpson recently read, a paper in London on this subject before the Institution of Electrical Engineers, in which the first part reviews overhead-conductor sags and tensions and. their calculation on single spans and on complete lines, using parabolic formulæ throughout. A standard procedure and standard methods of calculation are recommended. The second part of the paper deals with the determination, with respect to the conditions prevailing in Great Britain, of the wind and ice loads to be applied to conductors for design purposes, and the stresses so produced in the conductors. The. use of the term 'factor of safety' applied to overhead conductors is criticized, and suggestions are offered for revision of the Overhead Line Regulations of the Electricity Commissioners. The loads transmitted to the supports are also considered. Erection sags for low-voltage distribution lines are recommended for general adoption.

\section{Sheet Steels for Electrical Plant}

A PAPER entitled "A Survey of Electrical Sheet Steels for Power Plant and the Factors Affecting their Magnetic Properties" (J. Inst. Elect. Eng., 90, Pt. II, No. 17 ; October 1943) by Mr. F. Brailsford discusses magnetic sheet materials used for electrical plant, and represents an attempt to stimulate the interest of electrical engineers and others in this class of sheet steels, in which progress in relation to the commercial materials has been relatively slow. After a short discussion of the historical development, the limitations imposed upon designers of electrical plant by the existing materials are referred to. This is followed by a brief outline of the physical basis of magnetic processes and by a discussion of the factors which affect the magnetic properties of electrical sheets. Finally, reference is made to future possibilities. The problems involved in 